\title{
LAS SENTENCIAS LAUTSI EN EL CONTEXTO DE LA JURISPRUDENCIA DEL TRIBUNAL EUROPEO DE DERECHOS HUMANOS*
}

\author{
Fernando ARLETTAZ \\ DOCTOR EN DERECHO \\ INVESTIGADOR FPU \\ UNIVERSIDAD DE ZARAGOZA
}

SUMARIO: I. Introducción. II. Breve panorama de la jurisprudencia europea sobre la libertad religiosa y el derecho de los padres a educar a sus hijos en sus propias creencias. II.I. La libertad religiosa. II.2. El derecho de los padres a educar a sus hijos en sus propias creencias. III. Las sentencias en el caso Lautsi. IV. ¿Qué ha pasado desde entonces? V. Conclusiones. VI. Bibliografía citada.

RESUMEN: El artículo explora los rasgos fundamentales de las dos sentencias dictadas por el Tribunal Europeo de Derechos Humanos en el caso Lautsi c/Italia. Ellas son colocadas en el contexto general de la jurisprudencia de Estrasburgo sobre la libertad religiosa y el derecho de los padres a educar a sus hijos en sus propias creencias. Se realiza una evaluación crítica de la segunda sentencia. Finalmente, el caso Lautsi es puesto en relación con otras dos sentencias más recientes, también relativas a la expresión de las creencias religiosas en el espacio público.

Palabras ClaVE: símbolos religiosos, Tribunal Europeo de Derechos Humanos, libertad religiosa.

ABSTRACT: The article explores the main features of the two decisions by the European Court of Human Rights in Lautsi v. Italy. The decisions are placed in the general context of the jurisprudence of the Court on religious freedom and on the right of parents to educate their children according to their own beliefs. A critical perspective on the second sentence is adopted. Finally, the Lautsi case is confronted with two more recent sentences, also relating to the expression of religious beliefs in the public space.

KEYwORDS: religious symbols, European Court of Human Rights, religious freedom.

\section{Introducción}

En marzo de 2009 el Tribunal Europeo de Derechos Humanos dictó la sentencia de primera instancia en el caso Lautsi c/Italia. Un año más tarde, la Gran Sala dictó la sentencia de segunda instancia. Como es sabido, el cambio radical entre la decisión de la

\footnotetext{
* Este trabajo ha sido elaborado en el contexto del proyecto Consolider Ingenio 2010 El Tiempo de los Derechos (CSD 2008-0007).
} 
primera instancia (que declaró que la presencia de crucifijos en las escuelas italianas era una violación del derecho de los padres a educar a sus hijos en sus propias creencias en relación con la libertad religiosa de los propios menores) y la decisión de la segunda (que llegó a la conclusión exactamente inversa) ha sido objeto de muchas opiniones doctrinarias, no pocas de ellas sumamente críticas.

Más de dos años han transcurrido ya desde la sentencia de primera instancia. Y pronto se cumplirán dos años de la sentencia de segunda instancia. Parece pues un momento oportuno para rever las sentencias con cierta perspectiva, analizarlas y ver cuál ha sido el comportamiento posterior del Tribunal de Estrasburgo.

Comenzaremos este trabajo colocando las sentencias en el contexto general de la jurisprudencia del Tribunal en relación con la libertad religiosa y el derecho de los padres a educar a sus hijos en sus creencias. Luego pasaremos a un análisis detallado de las mismas, abordando especialmente la segunda y definitiva sentencia desde un ángulo crítico.

Finalmente, pondremos en relación el caso Lautsi con dos sentencias más recientes. Una de ellas se refiere a la presencia de crucifijos en los tribunales de justicia griegos. La otra, a una campaña pública de un grupo religioso que fue prohibida por el gobierno suizo.

\section{Breve panorama de la jurisprudencia europea sobre la libertad religiosa y el derecho de los padres a educar a sus hijos en sus propias creencias}

Para realizar el análisis que nos interesa en este trabajo, dos temas íntimamente relacionados resultan de interés: la interpretación que ha hecho el Tribunal Europeo de Derechos Humanos del artículo 9 del Convenio relativo a la libertad religiosa y la interpretación que ha hecho del artículo 2 del Protocolo i relativo al derecho de los padres a educar a sus hijos en sus propias creencias. Por supuesto no podemos sino hacer una breve panorámica al respecto, remitiendo para mayor profundidad a los trabajos especializados ${ }^{\mathrm{I}}$.

\section{II.I. La libertad religiosa}

La libertad religiosa ha sido objeto de una amplia consideración por la jurisprudencia de Estrasburgo. En primer lugar resulta de interés indicar que el Tribunal ha afirmado que esta libertad protege tanto el fuero interno como el fuero externo ${ }^{2}$. Ha sido, sin embargo, muy restrictivo acerca de qué conductas han de considerarse dentro del ámbito de protección del fuero interno. De hecho, los Estados deben actuar muy represivamente para que el Tribunal entienda que ha habido una restricción del fuero interior.

\footnotetext{
${ }^{\text {I }}$ Ver al respecto: ArLetTAZ, F., «La jurisprudencia del Tribunal Europeo de Derechos Humanos sobre la libertad religiosa: un análisis jurídico-político», en Derechos y Libertades, 27, 2012, págs. 209-240. CHUECA SANCHO, A., «El derecho humano a la libertad de religión y convicciones en una Europa intercultural», en AAVV, Teoría de la justicia y derechos fundamentales, Madrid, Dikynson, 2008, págs. 297-3I8. EvANs, C., Freedom of Religion under the European Convention on Human Rights, Oxford, Oxford University Press, 2003. FroweIn, J. A., «Article 9.I», en Pettiti, L.-E.; Decaux, E.; Imbert, P.-H., La Convention Européenne des Droits de l'Homme, París, Economica, I995, págs. 353-363. RYSSDAL, R., «Religious Freedom in the Case Law of the European Court of Human Rights», en Martínez-Torrón, J., La libertad religiosa y de conciencia ante la justicia constitucional, Granada, Comares, I998, págs. 87-93. TAYLOR, P., Freedom of Religion. UN and European Human Rights Law and Practice, Cambridge, Cambridge University Press, 2005.

${ }^{2}$ Tribunal Europeo de Derechos Humanos (TEDH) en el asunto Kokkinakis c/Grecia (25/05/1993), párrafo 3I. TEDH en el asunto Hassan y Tchaouch c/Bulgaria (16/10/2000), párrafo 66. TEDH en el asunto SvyatoMykhaylivska Parafiya c/Ucrania (I4/06/2007), párrafo II2. TEDH en el asunto Dogru c/Francia (04/I2/2008), párrafo 6I.
} 
En cuanto a las conductas externas, como ha dicho el Tribunal ${ }^{3}$, el artículo 9 protege un conjunto de manifestaciones posibles de la libertad religiosa, pero no todos los actos inspirados por motivos religiosos pueden quedar amparados. Tiene que haber una relación clara y evidente entre la convicción religiosa y su manifestación externa.

El fuero externo comprende en primer lugar los actos rituales o de culto, practicados individual o colectivamente, ya sea en un ámbito físico privado o público. Se incluyen, por ejemplo, la realización de servicios religiosos ${ }^{4}$ y la posibilidad de establecer un lugar dedicado al culto5.

También la enseñanza religiosa es una actividad protegida. Este concepto ha aparecido en casos de proselitismo, es decir, aquella actividad por medio de la cual los miembros de una religión buscan ampliar el número de sus adeptos. De acuerdo con la jurisprudencia, la actividad misionera no puede ser considerada una violación de la libertad de religión de los destinatarios de ella si todas las partes involucradas son adultos capaces de discernimiento y no hay relación de dependencia o jerarquía entre los misioneros y las personas destinatarias de la actividad proselitista ${ }^{6}$.

Esto no quiere decir que toda limitación de la actividad proselitista sea ilícita. El Tribunal ha establecido una distinción entre formas lícitas e ilícitas de proselitismo. Por eso resultan legítimas las limitaciones a la libertad religiosa, en su dimensión de proselitismo, cuando la persona que realiza la actividad proselitista intenta prevalerse de una relación de dependencia o jerarquía que la vincula con el destinatario de la actividad ${ }^{7}$.

Según el Convenio también están protegidas las prácticas religiosas. La libertad religiosa supone el derecho a vivir conforme a las propias creencias, a organizar la vida según ellas. Esto tiene amplísimas consecuencias: seguimiento de prescripciones alimenticias, respeto de días de descanso, cumplimiento de prácticas funerarias, y un largo etcétera. Sin embargo, para no elevar infinitamente la protección del artículo 9, el Tribunal Europeo se ha visto obligado a señalar que la libertad religiosa protege las manifestaciones que obedecen a fines religiosos, pero no necesariamente todo aquello que una religión obliga a realizar, y mucho menos todo aquello que ella permite realizar.

Dentro de las prácticas ocupa un lugar importante el vestido. Corresponde al fuero externo protegido el derecho de llevar las vestimentas que sean exigidas por las pautas del grupo religioso al que se pertenece. Sin dudas, el caso que ha generado mayor controversia a este respecto ha sido el del velo islámico. En particular, ha suscitado vivas reacciones el uso del burka o del niqab, dos formas tradicionales de vestimenta que cubren completamente la cara y el cuerpo de la mujer, así como el uso del velo islámico en general en el ámbito educativo. Aunque el Tribunal ha admitido como principio que vestir de acuerdo con las propias creencias religiosas es una manifestación protegida de la libertad religiosa, en general ha juzgado que las restricciones impuestas por los Estados en este campo eran legítimas ${ }^{8}$.

\footnotetext{
${ }^{3}$ TEDH en el asunto Dogru c/Francia (04/12/2008), párrafo 6I. TEDH en el asunto Leyla Sahin c/Turquía (I0/II/2005, Gran Sala), párrafo I07. TEDH en el asunto Leela Förderkreis E. V. y otros c/Alemania (06/ı/2008), párrafo 80.

4 TEDH en el asunto Barankevich c/Rusia (26/10/2007).

5 TEDH en el asunto Sagrados Monasterios c/Grecia (09/12/1994).

${ }^{6}$ TEDH en el asunto Kokkinakis c/Grecia (25/05/1993).

7 TEDH en el asunto Larissis, Mandalarides $y$ Sarandis c/Grecia (24/02/1998).

${ }^{8}$ TEDH en el asunto Dahlab c/Suiza (I5/O2/200I, decisión de inadmisibilidad). TEDH en el asunto Phull c/Francia (II/OI/2005, decisión de inadmisibilidad). TEDH en el asunto Lepla Sahin c/Turquía (io/II/2005, Gran Sala). TEDH en el asunto Köse y otros c/Turquía (24/oI/2006, decisión de inadmisibilidad). TEDH en el
} 
La libertad religiosa también incluye la observancia de reglas de alimentación establecidas por la comunidad a la que se pertenece, así como la realización de rituales para la obtención de esos alimentos ${ }^{9}$. El derecho individual a la alimentación conforme a las propias creencias puede generar algunas obligaciones positivas del Estado, como la obligación de proveer una alimentación adecuada en los establecimientos públicos como escuelas, prisiones, etc. Así, por ejemplo, el Estado tiene la obligación de proveer a las necesidades religiosas de los prisioneros en la medida de lo posible ${ }^{\mathrm{IO}}$.

La libertad religiosa puede ejercitarse individualmente o en grupo. Hay que recordar que, respecto de esto último, no se trata de la libertad religiosa como derecho colectivo sino del ejercicio colectivo de un derecho individual a la libertad religiosa. Por ello puede decirse que forma parte de las manifestaciones externas lícitas de la libertad religiosa, en su dimensión colectiva, el organizarse como comunidad asociándose a efectos del culto y del ejercicio de otras actividades religiosas o sociales vinculadas con la religión, ya que las comunidades religiosas existen tradicionalmente en forma de estructuras organizadas. El derecho de asociarse con fines religiosos está incluido en la libertad religiosa, que debe interpretarse a la luz de las normas que garantizan la libertad de asociación ${ }^{\text {II }}$.

El derecho de los fieles a la libertad de religión supone también la posibilidad de la existencia y funcionamiento pacíficos de las comunidades religiosas, lo que excluye cualquier injerencia arbitraria del Estado. Por otra parte, y como ha afirmado reiteradamente el Tribunal ${ }^{12}$, la autonomía de las comunidades religiosas es indispensable al pluralismo de una sociedad democrática y se encuentra en el corazón mismo de la protección ofrecida por el artículo 9.

La libertad religiosa tiene una dimensión negativa que corresponde tanto al fuero interno como al externo. De este modo, todo lo dicho antes en términos positivos, puede traducirse a su forma negativa: el derecho a formar, mantener, cambiar o abandonar las convicciones religiosas implica el derecho a no hacerlo; el derecho a participar en ceremonias o ritos implica el derecho de no hacerlo; el derecho a realizar actos de proselitismo religioso implica el derecho de no hacerlo; etc.

Un particular aspecto de esta dimensión negativa es el derecho a no declarar las propias creencias. Este derecho suele reconocerse como implícito en el Convenio Europeo. Por esa razón, por ejemplo, no debe incluirse mención de la religión en pasaportes, documentos de identidad $u$ otros documentos administrativos semejantes ${ }^{13}$. Esto no impide, sin embargo, que se imponga la carga de hacer públicas las propias ideas religiosas a quien pretende obtener un beneficio de ello (por ejemplo, obtener una autorización para ausentarse de su trabajo en un día de fiesta religiosa $)^{\mathrm{I4}}$.

La libertad religiosa no es un derecho ilimitado. De acuerdo con lo que establece el artículo 9 del Convenio, ella puede ser restringida por los Estados de acuerdo con ciertas reglas. La primera regla es que las restricciones que los Estados impongan en este ámbito

asunto El Morsli c/Francia (04/03/2008, decisión de inadmisibilidad). TEDH en el asunto Dogru c/Francia (08/I2/2008).

9 TEDH en el asunto Cha'are Shalom ve tsedek c/Francia (27/06/2000).

Io TEDH en el asunto Jakóbski c/ Polonia (07/12/2010).

II TEDH en el asunto Hassan y Tchaouch c/Bulgaria (I6/10/2000).

${ }^{12}$ TEDH en el asunto Hassan y Tchaouch c/Bulgaria (I6/IO/2000). TEDH en el asunto Svyato-Mykhaylivska Parafiya c/Ucrania (I4/06/2007). TEDH en el asunto Religionsgemeinschaft der Zeugen Jehovas $y$ otros c/Austria (3I/07/2008). TEDH en el asunto Rama Moscovita del Ejército de Salvación c/Rusia (05/10/2006).

${ }^{13}$ TEDH en el asunto Sinan Işik c/Turquía (02/02/2010).

${ }^{14}$ TEDH en el asunto Kosteski c/Antigua República Yugoeslava de Macedonia (13/04/2006). 
sólo pueden referirse al aspecto externo de la libertad religiosa, pero no al aspecto interno. A segunda regla es que para que la restricción sea legítima es necesario que se cumplan tres requisitos.

El primero de ellos es que la restricción esté prevista por la ley. Debe tratarse de una ley en sentido material, no necesariamente formal. Es decir, textos escritos y generales, aunque sean de rango inferior a las normas dictadas por la Legislatura; textos que pueden ser complementados por la jurisprudencia pertinente ${ }^{\mathrm{IS}}$.

El segundo requisito es que la restricción cumpla una finalidad legítima. Según la enumeración que hace el propio Convenio, los fines legítimos que justifican la restricción de la libertad religiosa son la protección de la seguridad pública, la protección del orden, de la salud o de la moral públicas, y la protección de los derechos o las libertades de los demás. Esta enumeración, ha dicho el Tribunal, es exhaustiva ${ }^{\mathrm{I}}$.

El tercer requisito es que la medida sea una medida necesaria en una sociedad democrática. En general ésta es la válvula que utiliza el Tribunal para decidir sobre la legitimidad o ilegitimidad de la restricción. Los dos criterios anteriores suelen ser flexiblemente interpretados por el Tribunal, que admite generalmente sin mayor inconveniente que la medida restrictiva está prevista por la ley y tiene una finalidad legítima.

Es en el contexto del tercer requisito que se ha desarrollado la conocida doctrina del margen de apreciación nacional. Ella busca lograr un equilibrio entre la protección internacional de los derechos humanos y el respeto de las peculiaridades propias del derecho nacional. El margen de apreciación se traduce en una relativización del concepto de necesidad en una sociedad democrática, permitiendo cierta libertad a las autoridades nacionales al momento de su interpretación. Se produce así un renvío a la discrecionalidad de la autoridad nacional en la apreciación de la situación de necesidad. De este modo, el Tribunal sólo invalida una restricción impuesta por la autoridad nacional cuando considera que ella ha excedido el razonable margen de discrecionalidad que tiene la autoridad nacional para apreciar la necesidad de la medida restrictiva en el contexto de una sociedad democrática.

La discrecionalidad nacional no es absoluta, porque la doctrina del margen de apreciación nacional no elimina el control europeo posterior; pero es sí muy amplia. En efecto, aunque el Tribunal ha dicho que los Estados sólo tienen un limitado margen de apreciación en este campo ${ }^{\mathrm{I7}}$, lo cierto es que en los hechos, y como veremos particularmente en relación con las sentencias Lautsi, la jurisprudencia europea ha sido muy a menudo demasiado flexible con las soluciones nacionales.

\section{II.2. El derecho de los padres a educar a sus hijos en sus propias creencias}

Según el artículo 2 del Protocolo I el Estado debe respetar el derecho de los padres a una educación y enseñanza de sus hijos conforme a sus convicciones religiosas y filosóficas. De acuerdo con el Tribunal Europeo, esto quiere decir, en primer lugar, que los padres tienen el derecho de ejercitar sus naturales funciones de educadores, aconsejando y

\footnotetext{
${ }^{15}$ TEDH en el asunto Dogru c/Francia (04/12/2008), párrafo 52, con cita de jurisprudencia anterior relativa a diversas libertades del Convenio, por ser un principio bien establecido en la jurisprudencia del Tribunal.

${ }^{16}$ TEDH en el asunto Svyato-Mykhaylivska Parafiya c/Ucrania (I4/06/2007), párrafo I32. TEDH en el asunto Iglesia de la Cienciología de Moscú c/Rusia (05/04/2007), párrafo 86.

${ }_{17}$ TEDH en el asunto Svyato-MYkhaylivska Parafiya c/Ucrania (I4/06/2007), párrafo II4. TEDH en el asunto Iglesia de la Cienciología de Moscú c/Rusia (05/04/2007), párrafo 87.
} 
orientado a sus hijos en conformidad con sus propias convicciones ${ }^{\mathrm{r}}$. Este derecho de los padres, por otra parte, ha de entenderse siempre en relación con el derecho del niño a ser educado $^{\text {I9 }}$.

El derecho de los padres a la formación moral y religiosa de sus hijos no es un derecho ilimitado. En primer lugar, por ser un derecho fundado en el derecho de los hijos a la educación, los padres no pueden rechazar la satisfacción de este derecho de los hijos, alegando sus propias creencias. Por eso el Estado puede establecer la obligatoriedad de la enseñanza, aún en contra de la voluntad de los padres, que no tienen un derecho a que su hijo sea eximido de la misma ${ }^{2 \circ}$. Además, la obligatoriedad de la enseñanza no priva a los padres de su derecho a educar a sus hijos, ya que pueden continuar la formación fuera del horario escolar ${ }^{2 \mathrm{I}}$.

Del derecho de los padres surge un conjunto de obligaciones estatales. El Estado debe, en primer lugar, abstenerse de impedir el ejercicio del derecho de los padres de educar y enseñar a sus hijos de acuerdo con sus propias creencias en el ámbito propiamente familiar. Pero las obligaciones del Estado son más amplias, porque de acuerdo con el Convenio el Estado no sólo tiene un deber de respetar el derecho de los padres de modo genérico, sino que este deber se extiende incluso al ejercicio de las funciones que asuma en el campo de la educación $y$ de la enseñanza, como expresa literalmente el propio artículo 2 del Protocolo I.

De acuerdo con la interpretación del Tribunal Europeo, este deber estatal se satisface mediante la garantía de que la educación brindada por el sistema público de enseñanza sea proporcionada de manera neutral $y$ objetiva: en otras palabras, el Estado no puede perseguir mediante la educación pública una finalidad de adoctrinamiento ${ }^{22}$.

Es prácticamente imposible que cierto número de asignaturas enseñadas en el colegio no tenga, de cerca o de lejos, un tinte o incidencia de carácter filosófico. Lo mismo ocurre con el carácter religioso, si se tiene en cuenta que las religiones suelen formar un conjunto dogmático y moral muy vasto, que tiene o puede tener respuestas a toda cuestión de orden filosófico, cosmológico o ético. Por eso, lo que se exige no es que los contenidos enseñados por el Estado estén libres de valores, sino que la transmisión de los mismos se haga de un modo neutral.

El establecimiento del curriculum es una competencia en la que el Estado goza de una cierta discrecionalidad, y las soluciones pueden variar según el país y la época ${ }^{23}$. Esto quiere decir que el Estado puede enseñar en los distintos niveles de la instrucción pública temáticas de carácter filosófico o religioso, ya que de otro modo la educación

\footnotetext{
${ }^{18}$ TEDH en el asunto Kjeldsen, Busk Madsen $y$ Pedersen c/ Dinamarca (07/I2/1976), párrafo 54.

I9 TEDH en el asunto Kjeldsen, Busk Madsen $y$ Pedersen c/ Dinamarca (07/12/1976), párrafo 52. TEDH en el asunto Campbell y Cosans c/Reino Unido (25/02/I982), párrafos 36-37. TEDH en el asunto Valsamis c/Grecia (18/ı2/ı996), párrafos 25 y 27. TEDH en el asunto Folgerø y otros c/Noruega (29/06/2007), párrafo 84. TEDH en el asunto Hasan y Eylem Zengin c/Turquía (09/10/2007), párrafo 50.

${ }^{20}$ TEDH en el asunto Konrad $y$ otros c/Alemania (II/09/2006, decisión de inadmisibilidad), apartado I del derecho aplicable.

${ }^{2 I}$ TEDH en el asunto Konrad $y$ otros c/Alemania (II/09/2006, decisión de inadmisibilidad), apartado I del derecho aplicable.

${ }^{22}$ TEDH en el asunto Kjeldsen, Busk Madsen y Pedersen c/Dinamarca (07/12/1976), párrafo 53. TEDH en el asunto Valsamis c/ Grecia (27/II/1996), párrafo 28. TEDH en el asunto Jiménez Alonso c/España (25/05/2000, decisión de inadmisibilidad), apartado I del derecho aplicable. TEDH en el asunto Folgerø y otros c/Noruega (29/06/2007), párrafo 84. TEDH en el asunto Hasan y Eylem Zengin c/Turquía (09/10/2007), párrafos 5I-52.

${ }^{23}$ TEDH en el asunto Kjeldsen, Busk Madsen y Pedersen c/Dinamarca (07/12/1976), párrafo 53. TEDH en el asunto Valsamis c/Grecia (I8/ı2/I996), párrafo 28. TEDH en el asunto Folgerø y otros c/Noruega (29/06/2007), párrafo 84. TEDH en el asunto Hasan y Eylem Zengin c/Turquía (09/10/2007), párrafo 5I.
} 
institucionalizada se volvería impracticable ${ }^{24}$. Al hacerlo, sin embargo, debe limitarse a exponer los diferentes puntos de vista sin tomar partido por ninguno de ellos. Es decir, la libertad de los padres de educar a sus hijos en sus propias creencias no es incompatible con una enseñanza del pluralismo que transmita la realidad social de la existencia de diferentes concepciones filosóficas y religiosas, siempre que en esta enseñanza el Estado guarde una actitud de imparcialidad.

Para saber si el Estado está efectivamente exponiendo de manera neutral y objetiva los contenidos de carácter religioso o filosófico, no basta con analizar los objetivos generales de la enseñanza. Se deben tener en cuenta también los contenidos concretos de los programas $^{25}$.

Por otra parte, además de las normas que regulan el modo en que se imparte la enseñanza, para que se pueda afirmar que ésta es dada de forma neutral y objetiva, hay que consultar también la forma real y concreta en que tales disposiciones legales se traducen en las prácticas dentro del aula. Esto es así porque los contenidos generales que se asignan a las materias educativas han de experimentar ulteriores concreciones a través del proyecto educativo de cada centro y los textos que se utilicen, así como de la manera en que se expongan ${ }^{26}$.

Claro que el solo hecho de que un programa otorgue mayor prioridad al conocimiento de determinadas corrientes religiosas o filosóficas frente a otras no es de por sí contrario a los principios de objetividad y pluralismo en la enseñanza ${ }^{27}$. La realidad histórica de una sociedad dada puede justificar que se dé prioridad al conocimiento de determinados sistemas de creencias. Ahora bien, aunque pueda otorgarse prioridad a determinados sistemas de creencias frente a otros, el requisito de objetividad y pluralismo en la enseñanza sólo se satisface si los programas de estudios dan un espacio a los diferentes sistemas de creencias presentes en la sociedad ${ }^{28}$.

Cuando el Estado va más allá de la mera exposición de valores religiosos o filosóficos entra en el terreno de la inculcación de valores. Esto sucede cuando el Estado no se limita a exponer formas de pensamiento de manera neutral y objetiva. ¿ Puede el Estado, en algún caso, inculcar en sus futuros ciudadanos determinados valores por medio de la enseñanza? Aquí la cuestión se plantea en un doble nivel. En primer lugar, respecto de los valores religiosos o filosóficos propios de un grupo de individuos. En segundo lugar, respecto de los valores que subyacen al ordenamiento constitucional del Estado en cuestión y que pueden presumirse como formando parte de los compromisos políticos básicos de la sociedad.

Respecto de los primeros, y según se ha venido exponiendo, la respuesta es negativa. La enseñanza pública que incluye instrucción obligatoria (en un sentido no meramente expositivo, sino en un sentido de adoctrinamiento) en una determinada religión o convicción filosófica es contraria al derecho de los padres a educar a sus hijos en sus propias creencias.

Claro que esto será así, en tanto que las ideas que inculca la escuela sean distintas de las que profesan los padres. Por ello, las asignaturas que impliquen una inmersión en

${ }^{24}$ TEDH en el asunto Kjeldsen, Busk Madsen $y$ Pedersen c/Dinamarca (07/12/1976), párrafo 53. TEDH en el asunto Hasan y Eylem Zengin c/Turquía (09/10/2007), párrafo 5I.

${ }_{25}^{25}$ TEDH en el asunto Valsamis c/ Grecia (27/II/I996), párrafo 27. TEDH en el asunto Hasan y Eylem Zengin c/Turquía (09/01/2008), párrafos 58-60.

${ }^{26}$ TEDH en el asunto Hasan y Eylem Zengin c/Turquía (09/10/2007), párrafo 49.

${ }^{27}$ TEDH en el asunto Hasan y Eylem Zengin c/Turquía (09/0I/2008), párrafo 63.

${ }^{28}$ TEDH en el asunto Hasan y Eylem Zengin c/Turquía (09/0I/2008), párrafos 65-70. 
una determinada religión o creencia serán conformes a los principios jurídicos en la materia si se presentan como optativas (de modo que los padres puedan decidir enviar a sus hijos a ellas), como alternativas con otras asignaturas equivalentes que no conlleven adoctrinamiento (de modo que los padres puedan optar por una de las asignaturas para sus hijos) o incluso como obligatorias si se prevé la posibilidad de una dispensa (de modo que los padres puedan decidir no enviar a sus hijos a ellas) $)^{29}$.

Para que la dispensa legitime el sistema de enseñanza religiosa obligatoria, es necesario que ella pueda ser alcanzada de manera no discriminatoria. Esto quiere decir que no es suficiente para legitimar la enseñanza religiosa en las escuelas la existencia de una posibilidad de dispensa sólo respecto de quienes pertenezcan a determinados grupos religiosos, dejando fuera a quienes no pertenezcan a ellos ${ }^{30}$. Y tampoco es compatible con la libertad de conciencia de los padres, el mecanismo que obliga a éstos a declarar sus propias creencias para obtener la dispensa ${ }^{3 \mathrm{I}}$.

Una consideración diferente parecerían tener aquellos contenidos que se corresponden con los valores constitucionalmente protegidos. Existirían en efecto determinados valores cuya transmisión es de interés público, y que deberían prevalecer frente al derecho de los padres. Se trataría de aquellos valores que constituyen el sustrato moral del sistema constitucional de una sociedad democrática y basada en los derechos humanos ${ }^{32}$. En este caso, sería lícito que el Estado no sólo expusiera objetivamente tales contenidos, sino que incluso promoviera la adhesión a ellos ${ }^{33}$. Sin embargo, este punto no es del todo claro en la jurisprudencia del Tribunal, y algunos votos disidentes se han pronunciado por hacer prevalecer el derecho de los padres inclusive en este caso $^{34}$.

${ }^{29}$ Ver al respecto ANDRÁssy, G., «Religious Education and State Schools», en History of European Ideas, 20, I995, págs. 742-755.

$3^{\circ}$ TEDH en el asunto Hasan y Eylem Zengin c/Turquía (09/0I/2008), párrafos 74-75.

${ }^{3 \mathrm{I}}$ TEDH en el asunto Folgerø y otros c/Noruega (29/06/2007), párrafos 98-I02. TEDH en el asunto Hasan $\gamma$ Eylem Zengin c/Turquía (09/01/2008), párrafo 73.

${ }^{32}$ Como es sabido, esta cuestión ha sido de gran actualidad en España en torno de la enseñanza de la asignatura conocida como Educación para la ciudadanía. Ver, respecto de este debate y respecto de la cuestión general tratada, Gómez SÁNCHEZ, Y., «Libertad religiosa y derecho a la educación: un comentario sobre la asignatura: 'Educación para la ciudadanía y los derechos humanos'», en Anuario de Derecho Eclesiástico del Estado, 24, 2008, págs. 3I3-336. LlamAZARES FERNÁNDEZ, D., Educación para la ciudadanía democrática y objeción de conciencia, Madrid, Dykinson, 20Io. Ruiz Miguel, A., «Educación para la ciudadanía: entre la neutralidad estatal y la objeción de conciencia», en Anuario de Filosofía del Derecho, 26, 20Io, págs. Io7-I46. MARTínRETORTILlo BAQUeR, L., «Los padres tendrán derecho preferente a escoger el tipo de educación que habrá de darse a sus hijos», en Anuario de Derecho Eclesiástico del Estado, 24, 2008, págs. 223-290. Moreno ANTÓn, M., «Proyección multicultural de la libertad religiosa en el ámbito escolar», en Revista General de Derecho Canónico $Y$ Derecho Eclesiástico del Estado, Io, 2006.

${ }_{33}$ Esta postura parece insinuarse en la sentencia del Tribunal Europeo de Derechos Humanos en el asunto Valsamis c/Grecia (27/II/I996), párrafo 3І. Sin embargo, el Tribunal no es concluyente en este aspecto. Frente a la reclamación de padres pertenecientes al grupo Testigos de Jehová de que su hija no participara en un desfile para la conmemoración de una fiesta nacional, el Tribunal señala que tales conmemoraciones sirven al interés público. Pero dice al mismo tiempo que se trata de una manifestación pacífica, y que por lo tanto no hay lesión alguna a las ideas pacifistas que profesan los padres. Queda pendiente la pregunta de si la decisión habría sido la misma en el caso de que hubiese habido efectivamente una lesión a las convicciones de los padres, pero ésta hubiese concurrido con un interés público.

34 En el asunto Valsamis c/Grecia (27/II/I996), que ya se comentó, la opinión disidente de los jueces Thór Vilhjálmsson y Jambrek parece abonar la hipótesis de que ni siquiera aquello que puede ser comúnmente visto como formando parte del sustrato de valores comunes a la sociedad ha de prevalecer frente a las conciencias individuales de los padres. Refiriéndose a la participación en un desfile para conmemorar una fiesta nacional, dicen: «Incluso si la participación de su hija [la hija de los demandantes] en un desfile era sólo por un día, y la sanción escolar por no haber participado en él no fue, en términos objetivos, severa, el episodio fue susceptible de trastornar tanto a los padres como a la muchacha [...]. Las conmemoraciones de eventos nacionales son valiosas para la mayoría de las personas, pero la familia Valsamis no tenía ninguna obligación de compartir esa opinión». 
El respeto de las convicciones de los padres debe existir en toda la educación estatal, sin distinguir entre las materias específicas de instrucción religiosa o filosófica y otras materias ${ }^{35}$. Hay que tener además en cuenta que las creencias de los padres pueden verse afectadas no sólo por el contenido teórico de una determinada asignatura, sino por las modalidades o actitudes que exige su cursado.

Claro que para que los padres puedan oponerse a las enseñanzas impartidas en las escuelas oficiales, es necesario que exista una verdadera injerencia con sus creencias filosóficas o religiosas en los términos antes señalados. Los padres no tienen un derecho ilimitado de oposición frente a cualquier enseñanza con la que no coincidan. Así, no implica una violación del derecho de los padres a educar a sus hijos en sus propias convicciones el hecho de que una legislación nacional les permita dispensar a sus hijos de la enseñanza religiosa, pero no les permita lo mismo respecto de otras asignaturas, como la educación sexual. Existe una diferencia de naturaleza entre la instrucción religiosa y la educación sexual: la primera difunde necesariamente doctrinas y no simples conocimientos; no ocurre lo mismo con la segunda ${ }^{36}$. Si la educación sexual es brindada en una manera objetiva y científica, no implica violación de derecho alguno de los padres, máxime cuando no afecta el derecho de éstos a aconsejar y educar a sus hijos fuera del horario de clases ${ }^{37}$.

\section{Las sentencias en el caso Lautsi}

Podemos ahora entrar en el análisis de las sentencias que nos interesan. En el muy conocido caso Lautsi, el Tribunal de Estrasburgo se refirió a la situación de las escuelas italianas que, en razón de la particular vinculación histórica que este Estado tiene con la Iglesia Católica, cuentan con crucifijos en las aulas ${ }^{38}$. En primera instancia se decidió que la exposición de este tipo de símbolos religiosos supone una violación del derecho de los padres a educar a sus hijos en sus propias creencias (artículo 2 del Protocolo i) en relación con la libertad religiosa de los propios menores (artículo 9).

El argumento de la primera instancia partió del hecho de que un crucifijo colocado en un aula puede ser considerado como un símbolo religioso fuerte. Literalmente, y con cita

35 TEDH en el asunto Kjeldsen, Busk Madsen $y$ Pedersen c/ Dinamarca (07/I2/I976), párrafo 5I. TEDH en el asunto Hasan y Eylem Zengin c/Turquía (09/I0/2007), párrafo 49. TEDH en el asunto Folgerø y otros c/Noruega (29/06/2007), párrafo 84.

${ }^{36}$ TEDH en el asunto Kjeldsen, Busk Madsen Y Pedersen c/Dinamarca (07/12/1976).

37 TEDH en el asunto Kjeldsen, Busk Madsen $y$ Pedersen c/Dinamarca (07/I2/I976), párrafo 54. TEDH en el asunto Jiménez Alonso c/España (25/05/2000, decisión de inadmisibilidad), apartado I del derecho aplicable.

$3^{8}$ Sobre la sentencia de primera instancia en el caso Lautsi véase AndreEsCU, G. A.; AndreesCU, L., «The European Court of Human Rights' Lautsi Decision: Context, Contents, Consequences» en Journal for the Study of Religions and Ideologies, 9-26, 20I0, págs. 47-74. CAÑAMARES ARribas, S., «La cruz de Estrasburgo. En torno a la sentencia Lautsi v. Italia del Tribunal Europeo de Derechos Humanos», en Revista General de Derecho Canónico y Derecho Eclesiástico del Estado, 22, 20Io. CAÑAmares ARribas, S., «Símbolos religiosos en un Estado democrático y plural», en Revista de Estudios Jurídicos de la Universidad de Jaén, Iо, 2010, págs. I-I9. Sobre ambas sentencias ver BARRERo ORTEGA, A., «El caso Lautsi: la cara y la cruz», en Revista Española de Derecho Constitucional, 94, 20I2, págs. 379-409. Evans, M. D., «Lautsi v. Italy: An Initial Appraisal», en Religion and Human Rights, 6-3, 20II, págs. 237-244. EvANS, M. D., «Neutrality in and after Lautsi v. Italy», en Temperman, J., The Lautsi Papers: Multidisciplinary Reflections on Religious Symbols in the Public School Classroom, La Haya, Martinus Nijhoff Publishers, 20I2, págs. 329-354. KolstAY, A., «Europe and the Sign of the Crucifix: on the Fundamental Questions», en Temperman, J., The Lautsi Papers: Multidisciplinary Reflections on Religious Symbols in the Public School Classroom, cit., págs. 355-383. LIU, H.-Y., «Restricting the Public Display of Religious Symbols by the State on the Grounds of Hate Speech?», en Temperman, J., The Lautsi Papers: Multidisciplinary Reflections on Religious Symbols in the Public School Classroom, cit., págs. 383-4I2. RoNCHI, P., «Crucifixes, Margin of Appreciation and Consensus: The Grand Chamber Ruling in Lautsi v. Italy», en Journal of Ecclesiastical Law, I3-3, 20II, págs. 287-297. Zoethout, C. M., «Rethinking Adjudication under the European Convention», en Temperman, J., The Lautsi Papers: Multidisciplinary Reflections on Religious Symbols in the Public School Classroom, cit., págs. 413-426. 
de un caso anterior en el que se había dado la misma calificación al velo islámico ${ }^{39}$, el Tribunal dijo que el crucifijo es un símbolo externo y poderoso cuya presencia no puede pasar desapercibida, y que puede incidir decisivamente en los alumnos teniendo particularmente en cuenta la edad de éstos ${ }^{40}$.

Por otra parte, se entendió que la presencia del crucifijo en el aula va más allá de un legítimo uso de símbolos en un determinado contexto histórico ${ }^{4 \mathrm{I}}$. La presencia del crucifijo en el aula hace ver que el Estado toma partido por el catolicismo. Este sentido puede ser fácilmente comprendido por los alumnos, que sienten que están siendo educados en un contexto marcado por una religión particular. El riesgo es particularmente serio en el caso de alumnos que pertenecen a minorías religiosas ${ }^{42}$.

Como ha dicho literalmente el Tribunal: «La libertad negativa no se limita a la ausencia de servicios religiosos o de enseñanza religiosa. Ella se extiende a las prácticas y a los símbolos que manifiestan, en general o en particular, una creencia, una religión o el ateísmo. Este derecho negativo merece una protección particular si es el Estado el que manifiesta una creencia y si la persona está ubicada en una situación de la que no se puede liberar o puede hacerlo solamente por medio de esfuerzos y sacrificios desproporcionados» ${ }^{43}$.

Sin embargo, un tiempo después de esta sentencia la Gran Sala revocó la decisión. La Gran Sala entendió que el deber del Estado de respetar las convicciones de los padres no estaba limitado al contenido del currículum escolar, sino que se extendía a todo el ejercicio de las funciones de educación y enseñanza, lo que obviamente incluye la organización del ambiente escolar ${ }^{44}$. Por otra parte, la Gran Sala aceptó también que el crucifijo es sobre todo un símbolo religioso. Y aunque sea cierto que el crucifijo tiene, además de su sentido religioso, otros sentidos posibles, esto no afecta el juicio que ha de hacerse sobre el mismo ${ }^{45}$.

Sin embargo, la Gran Sala se apartó del criterio de la primera instancia al considerar que aunque resulta comprensible que la presencia del crucifijo en el aula pueda ser percibida como una falta de respeto hacia las convicciones de los padres que no comparten esas creencias religiosas, esta falta de respeto no alcanza por sí misma para constituir una violación del artículo 2 del Protocolo I relativo al derecho de los padres a educar a sus hijos en sus propias creencias ${ }^{46}$. Por otra parte, la segunda instancia también sostuvo que no existe evidencia de que la presencia del crucifijo en el aula pueda tener alguna influencia sobre los alumnos mismos, que son personas jóvenes cuyas creencias están todavía en proceso de formación ${ }^{47}$.

También se dijo que la decisión acerca de si se debe perpetuar o no una tradición cae en principio dentro del margen de apreciación de los Estados. Esta idea se vería reforzada por el hecho de que existe en Europa una gran diversidad de desarrollos históricos y culturales entre los Estados ${ }^{48}$. Literalmente se ha dicho: «Según la Corte, la decisión de

\footnotetext{
39 TEDH en el asunto Dahlab c/Suiza (15/02/200I, decisión de inadmisibilidad).

$4^{\circ}$ TEDH en el asunto Lautsi c/Italia (OI/03/2010), párrafo 54.

${ }^{4 \mathrm{I}}$ TEDH en el asunto Lautsi c/Italia (OI/03/2010), párrafo 52.

$4^{2}$ TEDH en el asunto Lautsi c/Italia (OI/03/2010), párrafos 53 y 55.

43 TEDH en el asunto Lautsi c/Italia (OI/03/2010), párrafo 55.

${ }^{44}$ TEDH en el asunto Lautsi c/ Italia (18/03/2011, Gran Sala), párrafo 63.

${ }^{45}$ TEDH en el asunto Lautsi c/ Italia (I8/03/20II, Gran Sala), párrafo 66.

${ }^{46}$ TEDH en el asunto Lautsi c/ Italia (I8/03/20II, Gran Sala), párrafo 66.

47 TEDH en el asunto Lautsi c/ Italia (18/03/2011, Gran Sala), párrafo 66.

$4^{8}$ TEDH en el asunto Lautsi c/ Italia (I8/03/20II, Gran Sala), párrafo 68.
} 
perpetuar o no una tradición corresponde en principio al margen de apreciación del Estado demandado. La Corte tiene además que tener en cuenta el hecho de que Europa se caracteriza por una gran diversidad entre los Estados que la componen, particularmente sobre el plano de la evolución cultural e histórica [‥] Desde este punto de vista, es cierto que al establecer la presencia del crucifijo en las aulas de las escuelas públicas - el que, reenvíe o no a valores laicos, referencia indudablemente al cristianismo -, la reglamentación da a la religión mayoritaria del país una visibilidad preponderante en el ambiente escolar. Sin embargo, esto no alcanza en sí para caracterizar la situación como un caso de adoctrinamiento por parte del Estado demandado» ${ }^{49}$. Por todo ello, los Estados gozan de un espacio de discrecionalidad para conciliar el ejercicio de las funciones que asumen en relación con la educación y la enseñanza, por un lado, y el derecho de los padres a la educación y enseñanza de sus hijos de acuerdo con sus convicciones, por el otro ${ }^{50}$.

El Tribunal dijo que tiene el deber de respetar las decisiones tomadas dentro de ese margen de apreciación, siempre que ellas no equivalgan a una forma de adoctrinamiento $^{51}$. En efecto, como vimos más arriba, el límite al ejercicio de las potestades estatales en este ámbito, de acuerdo con el criterio interpretativo bien asentado de Estrasburgo, es la prohibición de adoctrinamiento.

Se admitió que, al establecer la presencia de crucifijos en las aulas, el Estado italiano confiere a una religión concreta, en este caso el catolicismo, una visibilidad preponderante de la que no gozan otras religiones. Sin embargo, esta preponderancia no equivale, en el juicio del Tribunal, a un proceso de adoctrinamiento ${ }^{52}$. En este punto, la Gran Sala cita dos precedentes en los que se había afirmado que el hecho de que un currículum escolar diera más espacio en la enseñanza de las características de determinadas tradiciones religiosas por encima de otras no constituía una violación de derechos del Convenio ${ }^{53}$. Esta idea se reforzaría por la ausencia de un criterio europeo unificado acerca de la presencia de símbolos religiosos en las aulas ${ }^{54}$.

Además, el crucifijo sería un símbolo religioso puramente pasivo, no comparable al discurso didáctico usado por los maestros o a la participación en actividades religiosas ${ }^{55}$. Previendo una crítica en relación con el diferente criterio que esto supone respecto de otro caso en el que el Tribunal juzgó que el velo islámico era un símbolo religioso fuerte que podía afectar a los alumnos, la Gran Sala se apresuró a decir que, en aquel caso, sólo se había juzgado que la prohibición entraba dentro del margen de apreciación del Estado sin ir más allá (diciendo, por ejemplo, que la prohibición era necesaria según el Convenio) ${ }^{56}$.

La presencia de los crucifijos en las aulas debería ser puesta en relación con otros hechos según el Tribunal. En primer lugar, que en las escuelas italianas no hay enseñanza obligatoria de la religión cristiana. En segundo lugar, que Italia abre el espacio escolar a otras religiones (por ejemplo, no se prohíbe el uso del velo islámico o de otros símbolos religiosos, clases voluntarias de religión pueden ser organizadas en las escuelas en relación

\footnotetext{
49 TEDH en el asunto Lautsi c/ Italia (18/03/2011, Gran Sala), párrafo 68.

${ }^{\circ}$ TEDH en el asunto Lautsi c/ Italia (18/03/20II, Gran Sala), párrafo 69.

${ }^{51}$ TEDH en el asunto Lautsi c/ Italia (I8/03/20II, Gran Sala), párrafo 69.

$5^{2}$ TEDH en el asunto Lautsi c/ Italia (I8/03/20II, Gran Sala), párrafo 7I.

53 TEDH en el asunto Folgerø y otros c/Noruega (29/06/2007). TEDH en el asunto Hasan y Eylem Zengin c/Turquía (09/0I/2008).

54 TEDH en el asunto Lautsi c/ Italia (I8/03/20II, Gran Sala), párrafo 70.

55 TEDH en el asunto Lautsi c/ Italia (18/03/2011, Gran Sala), párrafo 72.

${ }_{56}^{6}$ TEDH en el asunto Lautsi c/ Italia (I8/03/20II, Gran Sala), párrafo 73.
} 
con todos los cultos reconocidos, etc.). En tercer lugar, que no se ha indicado que la presencia del crucifijo estuviera asociada al proselitismo religioso ${ }^{57}$.

Finalmente, el Tribunal hace notar que la presencia del crucifijo en nada impide a los padres continuar en el ejercicio de sus funciones naturales de educadores de sus hijos de acuerdo con sus propias convicciones (fuera del ámbito escolar, se sobrentiende) ${ }^{58}$.

La sentencia de segunda instancia ha sido objeto de una pléyade de críticas. Es cierto que el tema es complejo, como lo son la gran mayoría de los temas que conciernen la interpretación de una norma genérica relativa a derechos humanos. Sin embargo, como señalaremos a continuación, la gran mayoría de estas críticas son consistentes y muestran que la decisión de la segunda instancia no sólo ha sido incongruente con decisiones previas sino que además ha sido políticamente insatisfactoria.

Para afirmar que la injerencia no excede de lo legítimo el Tribunal recurre a su doctrina, asentada en fallos anteriores, según la cual el derecho de educación que corresponde a los padres en cuestiones religiosas se ve violentado cuando hay un adoctrinamiento de parte del Estado. Sin embargo, el Tribunal cree que la mera presencia del símbolo religioso en el aula no alcanza para configurar tal adoctrinamiento.

Teniendo en cuenta además que, de acuerdo con lo que la propia sentencia de segunda instancia afirma, la obligación del Estado de respetar el derecho de los padres se refiere no sólo a los contenidos enseñados sino a todo el ejercicio de la función educativa del Estado, no se alcanza a ver cómo es posible llegar a la conclusión a la que se llega. El ejercicio de la función educativa comprende también la organización del contexto escolar, según la misma Gran Sala lo admite. Si esto es así, ¿por qué un claro mensaje de promoción de una tradición religiosa no es una forma de adoctrinamiento? Que el Estado promueve una determinada creencia religiosa es algo admitido por la propia sentencia, cuando dice que por medio de la presencia del crucifijo se da al catolicismo una visibilidad preponderante de la que no gozan otras religiones. Que el ambiente escolar, a través del cual se promueve esa creencia, debe respetar los derechos de los padres también es admitido. Entonces, ¿por qué no se llega a la conclusión que parece obvia, esto es, que el crucifijo implica adoctrinamiento?

La solución de la primera instancia había sido mucho más clara en este punto. Admitía que el crucifijo es un símbolo religioso fuerte y que puede tener una significativa influencia en los alumnos. Éstos, en efecto, son compulsivamente llevados a un contexto (el de la escuela obligatoria) que está marcado por una tradición religiosa concreta.

Por otra parte, la sentencia pone de manifiesto la existencia de una doble vara de medir en el seno del Tribunal59. En efecto, tratándose de un crucifijo, símbolo cristiano, el Tribunal sostiene que no puede ser considerado como un símbolo religioso fuerte que implique adoctrinamiento, sino que es un símbolo religioso pasivo. Sin embargo, tratándose del velo islámico, el Tribunal ha llegado a la conclusión exactamente inversa, y ha avalado las decisiones nacionales en el sentido de su prohibición en determinados espacios.

Es verdad, como el Tribunal sostiene, que en los casos anteriores no había dicho que la prohibición de velo era necesaria en virtud del Convenio. Sólo se había afirmado que tal prohibición entraba dentro del legítimo margen de apreciación nacional. Sin embargo, si la prohibición estaba dentro del margen de apreciación nacional era precisamente, porque

\footnotetext{
57 TEDH en el asunto Lautsi c/ Italia (18/03/20II, Gran Sala), párrafo 74.

$5^{8}$ TEDH en el asunto Lautsi c/ Italia (I8/03/20II, Gran Sala), párrafo 75.

59 Ronchi, P., «Crucifixes, Margin of Appreciation and Consensus: The Grand Chamber Ruling in Lautsi v. Italy», cit., pág. 296. BARRERO ORTEGA, A., «El caso Lautsi: la cara y la cruz», cit., pág. 393.
} 
al ser visto como un signo religioso fuerte el uso del velo podía generar presión sobre terceros, y el Estado podía legítimamente impedir esta presión.

El Tribunal parece insinuar que la presencia del símbolo religioso en el aula puede ser considerada como una simple invitación a un sentido religioso, y no como una imposición $^{60}$. Esta perspectiva tiene varios inconvenientes. El primero es que dado que el símbolo es colgado en el aula por la decisión de una autoridad en el ejercicio de funciones públicas no parece que sea posible eludir cierto carácter coactivo en el sentido de que el crucifijo muestra, precisamente, que el poder coactivo del Estado se identifica con una determinada confesión. Además, no se debe olvidar que la escolarización de los niños y jóvenes es obligatoria, al menos hasta cierta edad, por lo que la presencia de un crucifijo en un aula equivale a la obligación impuesta a niños y jóvenes de estar sistemáticamente bajo el amparo un símbolo religioso en el transcurso de su formación. Un tercer inconveniente ya ha sido sugerido: ¿por qué el crucifijo en un aula es una invitación a un sentido religioso, mientras que un velo islámico, incluso llevado por un particular, es una imposición que afecta a terceros?

Pero supongamos por un momento que no existe adoctrinamiento. Podría pensarse que aunque el Estado no adoctrina al menos está tratando de modo radicalmente diferente al catolicismo en relación con otras religiones. ¿No implicaría esto acaso una violación de la igualdad en relación con la libertad religiosa? La Gran Sala se niega a entrar en esta cuestión (la Sala tampoco había considerado el ángulo de la igualdad, pero porque le había bastado con considerar la libertad religiosa en sí misma y los derechos de los padres para hallar una violación del Convenio). Sin embargo, no parece desacertado afirmar que el crucifijo hace sentir a quienes no pertenecen a la tradición religiosa favorecida que están excluidos de la comunidad de ciudadanos ${ }^{6 \mathrm{I}}$.

El Tribunal cita jurisprudencia anterior en la que se había afirmado que el hecho de que el currículum escolar diera un peso preponderante al conocimiento de una determinada tradición religiosa no implicaba de por sí una violación del Convenio. Esto es cierto, como vimos más arriba. Sin embargo, lo que el Tribunal olvida es que en todos esos casos se llegó a la conclusión de que el mayor énfasis puesto en el conocimiento de una determinada tradición religiosa no era ilegítimo pero sólo con la condición de que se tratara de un conocimiento transmitido de manera neutral $y$ objetiva. Es decir, lo que el Tribunal había admitido en sentencias anteriores era que, en el contexto de asignaturas que tenían por finalidad transmitir conocimientos acerca de las tradiciones religiosas (y no instruir activamente en la fe y práctica de una tradición religiosa) era posible que el Estado diera mayor importancia a aquellas tradiciones que estaban vinculadas a su trasfondo cultural e histórico. El límite, en cualquier caso, seguía siendo la prohibición de adoctrinamiento, es decir, el paso de una enseñanza dada en términos de transmisión de conocimientos objetivos a una enseñanza dada en términos de promoción de una tradición religiosa e inmersión activa en su fe y prácticas. Sin embargo, la promoción de una tradición religiosa es precisamente lo que hace el gobierno italiano al colgar los crucifijos en las aulas.

Finalmente, una buena parte del razonamiento del Tribunal está asentado en que debe aplicarse la doctrina del margen de apreciación nacional en razón de la falta de un criterio europeo unificado en esta materia. Esta afirmación, sin embargo, es problemática. En la mayoría de las escuelas públicas europeas no hay símbolos religiosos. Hay además pronunciamientos de las más altas instancias jurisdiccionales internas que han hecho

\footnotetext{
${ }^{60}$ Sobre los símbolos religiosos en los espacios públicos en Italia, y en particular sobre la cuestión de si el símbolo es una invitación o una imposición de sentido ver OlIVETTI, M., «Principio de laicidad y símbolos religiosos en el sistema constitucional italiano: la controversia sobre la exposición del crucifijo en las escuelas públicas», en Revista Catalana de Dret Public, 39, 2009, págs. 243-276.

${ }^{6 r}$ Ronchi, P., «Crucifixes, Margin of Appreciation and Consensus: The Grand Chamber Ruling in Lautsi v. Italy», cit., pág. 294.
} 
prevalecer la neutralidad estatal y la libertad religiosa negativa por sobre la presencia de los símbolos ${ }^{62}$.

\section{IV. ¿Qué ha pasado desde entonces?}

Más o menos por la misma época en la que el Tribunal analizaba el caso de los crucifijos en las aulas, llegó a sus estrados una demanda relativa a la presencia de crucifijos en los tribunales de justicia griegos. La Corte de Estrasburgo, sin embargo, no entró a analizar a fondo la cuestión porque consideró que los demandantes no habían sufrido ningún perjuicio. Éstos invocaban la violación no de la libertad religiosa (artículo 9 del Convenio, como ya sabemos) sino de la imparcialidad de los tribunales de justicia (artículo 6 del Convenio). Sin embargo, según el criterio del Tribunal Europeo no podían probar que en razón de esa sola presencia hubiesen sufrido un perjuicio demostrable; y de acuerdo con la jurisprudencia de Estrasburgo no existe en el sistema del Convenio una acción popular que pueda ser ejercitada por cualquier persona, sino que es necesario que quien ejercita la acción pueda demostrar haber sufrido un perjuicio directo ${ }^{63}$.

Seguramente la decisión en este caso fue técnicamente correcta y el error fue de los demandantes por no plantear la cuestión como un asunto de libertad religiosa. Es de lamentar que no haya existido la posibilidad de conocer la posición de Estrasburgo sobre los crucifijos colocados en ámbitos diferentes de las escuelas. En cualquier caso, teniendo en cuenta el precedente Lautsi y la amplia mayoría con la que fue aprobado por la Gran Sala, la respuesta del Tribunal habría sido probablemente la de la ausencia de violación del artículo 9.

Otro caso resuelto recientemente se refería a una cuestión parecida. El caso fue planteado por una agrupación religiosa conocida como Movimiento Raeliano. La doctrina de esta organización está basada en un supuesto contacto con los Elohim (extraterrestres con avanzada tecnología) que habrían creado la vida en la tierra y las diferentes religiones. El movimiento cree que el progreso científico y técnico es de fundamental importancia, y que la clonación y la transferencia de conciencia permitirán que el hombre llegue a la inmortalidad. Por otro lado, la agrupación tiene un particular punto de vista sobre la sexualidad que ha hecho que en algunos casos sus miembros fueran vinculados con casos de abuso infantil.

En el año 200I la asociación solicitó autorización administrativa a la ciudad de Neuchâtel, en Suiza, para realizar una campaña de posters. Estos posters incluían la frase $E l$ mensaje de los extraterrestres, la página web de la asociación y un número de teléfono. En el centro había imágenes de extraterrestres, una pirámide, un plato volador y la Tierra. A pesar de que campañas públicas, con un mensaje parecido al de la mencionada, habían sido autorizadas en varias ciudades de Suiza, el gobierno de Neuchâtel se opuso a ellas.

Aunque no se trata de un símbolo religioso tradicional, como el crucifijo, la analogía con éstos es evidente. Así como las religiones tradicionales utilizan símbolos tradicionales, los nuevos movimientos religiosos se valen de posters e indicaciones de páginas web. La diferencia más importante con el caso Lautsi no es el símbolo en sí mismo (aunque externamente sean muy diferentes, en ambos casos se trata de la expresión de las propias convicciones sobre las cuestiones últimas de la vida humana, es decir, de expresiones religiosas), sino que en el caso del Movimiento Raeliano no se trataba de símbolos religiosos que identificaran al Estado con una religión. El Estado sólo debía

\footnotetext{
${ }^{62}$ BARrero ORTEGA, A., «El caso Lautsi: la cara y la cruz», cit., págs. 392-393.

${ }_{6}$ TEDH en el asunto Dimitras $y$ otros c/Grecia II (03/II/20II).
} 
intervenir dando (o negando, como de hecho sucedió) su autorización para que un grupo de particulares realizara una manifestación religiosa en el espacio público.

Esta diferencia es esencial y ayuda a comprender mejor el caso Lautsi. En efecto, y en contra de lo que algunos opinan ${ }^{64}$, lo que estaba en juego en Lautsi no era la libertad religiosa colectiva de los católicos. Los católicos pueden seguir ejerciendo su libertad religiosa, individual y colectivamente, haya o no haya crucifijos en las aulas. Retirar un crucifijo del muro de un aula no es equivalente a retirarlo del altar de una iglesia, y tampoco impide a los católicos que lleven crucifijos colgados en su pecho. En Lautsi estaba en juego la cuestión de si el Estado puede o no identificarse con una tradición religiosa, afectando de este modo la libertad religiosa negativa de quienes no forman parte de esa comunidad. En cambio, en el caso Movimiento Raeliano sí estaba en juego la dimensión colectiva (y positiva) de la libertad religiosa de un grupo (aunque el Tribunal sólo se haya referido a la libertad de expresión).

La asociación presentó una demanda ante el Tribunal de Estrasburgo, alegando la violación de la libertad de expresión y de la libertad religiosa. La primera instancia del Tribunal sólo se refirió a la violación de la libertad de expresión, y consideró que no era necesario hacerlo respecto de la libertad religiosa. En este sentido, la Sala entendió que la prohibición era una interferencia legítima con la libertad de expresión porque estaba prescrita por la ley y tenía una finalidad legítima (que era la prevención del crimen, la protección de la salud y la moral y la protección de los derechos de terceros). La prohibición podía ser considerada como necesaria en una sociedad democrática: aunque los posters no tenían en sí mismos nada de ilegal o chocante, presentaban la página web de la asociación tornándola accesible a un amplio número de personas, incluidas menores. Dado el contenido de estas páginas, su publicidad podría considerarse inapropiada. Teniendo en cuenta además que los órganos jurisdiccionales internos habían motivado sus decisiones al avalar la prohibición, y también el carácter restringido de la misma (que no prohibía la asociación y sus actividades, sino sólo una concreta campaña pública), la Sala entendió que la prohibición entraba dentro del margen de apreciación dejado a las autoridades nacionales ${ }^{65}$.

La Gran Sala ratificó la sentencia de primera instancia. Al igual que ella sólo se refirió a la alegada violación de la libertad de expresión, dejando fuera la consideración de la libertad religiosa. Respecto de la libertad de expresión, se aceptó que la medida prohibitiva estaba basada en la ley. También que perseguía fines legítimos. El Tribunal también consideró que la prohibición cumplía el requisito de necesidad en una sociedad democrática, refiriéndose nuevamente a la conocida doctrina del margen de apreciación nacional. Teniendo en cuenta la amplitud del margen de apreciación nacional en este $\operatorname{caso}^{66}$, la segunda instancia concluyó que sólo razones serias pueden hacer que el juicio de las autoridades internas sea sustituido por el del Tribunal internacional. Sin embargo, el Tribunal no encontró esos fuertes motivos para apartarse del juicio de las autoridades nacionales ${ }^{67}$.

Aunque, como ya dijimos, el caso difiere en su sustancia del presentado en Lautsi y la base de análisis fue diferente (se consideró la libertad de expresión, no la libertad religiosa) el sustento de la decisión fue el mismo: el reenvío al margen de apreciación de la

\footnotetext{
${ }^{64}$ KolstAY, A., «Europe and the Sign of the Crucifix: on the Fundamental Questions», cit., pág. 36r.

${ }^{6}$ TEDH en el asunto Movimiento Raeliano de Suiza c/ Suiza (I3/OI/20II).

${ }^{66}$ La extensión de este margen de apreciación varía según la naturaleza del discurso que se entiende protegido por la libertad de expresión. Así, mientras el margen de apreciación es estrecho en relación con el discurso político, es más amplio en relación con aquellos discursos que pueden ofender convicciones personales íntimas en la esfera de la moral o, especialmente, de la religión. Del mismo modo, los Estados tienen un amplio margen de apreciación en relación con los discursos que tengan finalidades comerciales o publicitarias.

${ }^{67}$ TEDH en el asunto Movimiento Raeliano de Suiza c/ Suiza (13/07/2012, Gran Sala).
} 
autoridad nacional. De acuerdo con la jurisprudencia, en materia de expresión religiosa en el espacio público, tanto si la expresión es del propio Estado como si es de particulares, los Estados gozan de un amplio margen de maniobra. Sin embargo, es de hacer notar que, a diferencia del caso Lautsi que fue resuelto por una amplia mayoría, el caso Movimiento Raeliano fue decidido por nueve votos contra ocho. Los votos disidentes consideraron que no había una necesidad social imperiosa que tornara la restricción a la libertad de expresión necesaria en una sociedad democrática.

\section{Conclusiones}

La segunda sentencia en el caso Lautsi significó, como hemos visto a lo largo de este trabajo, un giro radical respecto de la sentencia de primera instancia. La doctrina jurídica especializada formuló importantes críticas a este cambio de posición.

Más allá de que en efecto hay algunas cuestiones que pueden resultar opinables, como la mayoría de los complejos temas interpretativos que suscitan los documentos internacionales de derechos humanos, lo que sí resulta innegable en este caso es que, por un lado, el Tribunal Europeo ha dejado abierta una puerta demasiado grande para la discrecionalidad estatal y, por otro lado, la sentencia es dudosamente coherente con los precedentes del propio Tribunal.

Lo primero es inquietante. En efecto, al encuadrar la presencia de los crucifijos en el marco general de la doctrina del margen de apreciación nacional el Tribunal ha abdicado de ejercer su potestad de control sobre la decisión de las autoridades italianas. Aunque es innegable que la doctrina del margen de apreciación nacional puede resultar útil y necesaria en algunos casos para evitar que la jurisdicción europea ahogue la autonomía legislativa y gubernativa de los Estados, parece sin embargo que en este caso el Tribunal Europeo ha sido demasiado benevolente con Italia.

Lo segundo es más inquietante todavía. La coherencia de una sentencia judicial con los precedentes es un requisito indispensable para garantizar la igualdad de los ciudadanos ante la ley. Situaciones semejantes deben ser resueltas de modo semejante, de lo contrario se generarán situaciones de arbitraria discriminación. En el caso Lautsi, en cambio, el Tribunal ha olvidado sus propios precedentes en la materia. Ha olvidado que en otros casos relativos a la educación pública había dicho que el Estado no puede adoctrinar a los alumnos en contra de la voluntad de sus padres o de quienes hagan sus veces. Y ha olvidado también que había afirmado que otros símbolos religiosos, particularmente el velo islámico, pueden ser considerados símbolos religiosos fuertes susceptibles de provocar una impresión que, cree curiosamente el Tribunal, no provoca la imagen de una persona moribunda torturada en una cruz.

Las razones para preocuparse se incrementan todavía más si se considera que el fondo de esta diferencia de trato parece encontrarse en la existencia de cierto prejuicio hacia el Islam, como puede constatarse de la lectura de los considerandos de algunas sentencias. El crucifijo es el símbolo de una religión mayoritaria en Italia, es un objeto cuya presencia en lugares públicos está socialmente normalizada y que es además avalada por el Estado. El velo, en cambio, es el símbolo de una religión minoritaria y extraña, que se asocia a los fenómenos migratorios y, por ello, a la llegada de personas no normalizadas.

En dos casos posteriores a Lautsi el Tribunal se ha referido nuevamente a la expresión religiosa. El primero que citamos es un caso relativo a la presencia de crucifijos en los tribunales griegos. Es de lamentar que la demanda haya sido planteada como un supuesto de violación de la imparcialidad de los tribunales y no como un supuesto de libertad religiosa. Si se hubiera demando ante Estrasburgo por la violación de la libertad religiosa habríamos tenido ocasión de ver si se replicaba (como era de esperar), en el caso 
de los símbolos religiosos en los tribunales de justicia, el criterio de los símbolos religiosos en las aulas.

El segundo caso citado se refería a la expresión religiosa de particulares en el espacio público. Con recurso nuevamente a la doctrina del margen de apreciación nacional el Tribunal convalidó la prohibición que había hecho una ciudad suiza a la realización de una campaña de posters. De este modo, el Tribunal parece insistir en que tratándose de símbolos religiosos, ya sea de símbolos que implican una identificación del Estado o ya sea de símbolos colocados por particulares en el espacio público, el criterio fundamental es la discrecionalidad nacional.

Habrá que esperar nuevas ocasiones para ver cómo continúa esta gran novela. Sin embargo, dada la amplia mayoría con la que fue resuelto el caso Lautsi por la Gran Sala, no parece que sea de prever un cambio de criterio en el corto plazo.

\section{Bibliografía citada}

ANDRÁSSY, G., «Religious Education and State Schools», en History of European Ideas, 20, 1995, págs. 742-755.

Andreescu, G. A.; Andreescu, L., «The European Court of Human Rights' Lautsi Decision: Context, Contents, Consequences», en Journal for the Study of Religions and Ideologies, 9-26, 2010, págs. 47-74.

ArlettAZ, F., «La jurisprudencia del Tribunal Europeo de Derechos Humanos sobre la libertad religiosa: un análisis jurídico-político», en Derechos y Libertades, 27, 20I2, págs. 209-240.

Barrero Ortega, A., «El caso Lautsi: la cara y la cruz», en Revista Española de Derecho Constitucional, 94, 20I2, págs. 379-409.

CAÑAmares Arribas, S., «La cruz de Estrasburgo. En torno a la sentencia Lautsi v. Italia del Tribunal Europeo de Derechos Humanos», en Revista General de Derecho Canónico y Derecho Eclesiástico del Estado, 22, 20 Iо.

CAÑAmares Arribas, S., «Símbolos religiosos en un Estado democrático y plural», en Revista de Estudios Jurídicos de la Universidad de Jaén, IO, 20I0, págs. I-I9. Sobre ambas sentencias ver

Chueca SAncho, A., «El derecho humano a la libertad de religión y convicciones en una Europa intercultural», en AAVV, Teoría de la justicia y derechos fundamentales, Madrid, Dikynson, 2008, págs. 297-318.

Evans, C., Freedom of Religion under the European Convention on Human Rights, Oxford, Oxford University Press, 2003 .

Evans, M. D., «Lautsi v. Italy: An Initial Appraisal», en Religion and Human Rights, 6-3, 20II, págs. 237-244.

Evans, M. D., «Neutrality in and after Lautsi v. Italy», en Temperman, J., The Lautsi Papers: Multidisciplinary Reflections on Religious Symbols in the Public School Classroom, La Haya, Martinus Nijhoff Publishers, 20I2, págs. 329-354.

Frowein, J. A., «Article 9.I», en Pettiti, L.-E.; Decaux, E.; Imbert, P.-H., La Convention Européenne des Droits de l'Homme, París, Economica, I995, págs. 353-363.

GómEZ SÁNCHEZ, Y., «Libertad religiosa y derecho a la educación: un comentario sobre la asignatura: 'Educación para la ciudadanía y los derechos humanos'», en Anuario de Derecho Eclesiástico del Estado, 24, 2008, págs. 313-336.

Kolstay, A., «Europe and the Sign of the Crucifix: on the Fundamental Questions», en Temperman, J., The Lautsi Papers: Multidisciplinary Reflections on Religious Symbols in the Public School Classroom, cit., págs. 355-383.

LiU, H.-Y., «Restricting the Public Display of Religious Symbols by the State on the Grounds of Hate Speech?», en Temperman, J., The Lautsi Papers: Multidisciplinary Reflections on Religious Symbols in the Public School Classroom, cit., págs. 383-412.

LlAmaZARES FernándeZ, D., Educación para la ciudadanía democrática y objeción de conciencia, Madrid, Dykinson, 2010.

MARTín-Retortillo Baquer, L., «Los padres tendrán derecho preferente a escoger el tipo de educación que habrá de darse a sus hijos», en Anuario de Derecho Eclesiástico del Estado, 24, 2008, págs. 223-290.

Moreno Antón, M., «Proyección multicultural de la libertad religiosa en el ámbito escolar», en Revista General de Derecho Canónico y Derecho Eclesiástico del Estado, Io, 2006. 
OlivetTI, M., «Principio de laicidad y símbolos religiosos en el sistema constitucional italiano: la controversia sobre la exposición del crucifijo en las escuelas públicas», en Revista Catalana de Dret Public, 39, 2009, págs. $243-276$.

Ronchi, P., «Crucifixes, Margin of Appreciation and Consensus: The Grand Chamber Ruling in Lautsi v. Italy», en Journal of Ecclesiastical Law, I3-3, 20II, págs. 287-297.

Ruiz Miguel, A., «Educación para la ciudadanía: entre la neutralidad estatal y la objeción de conciencia», en Anuario de Filosofía del Derecho, 26, 2010, págs. 107-146.

Ryssdal, R., «Religious Freedom in the Case Law of the European Court of Human Rights», en MartínezTorrón, J., La libertad religiosa y de conciencia ante la justicia constitucional, Granada, Comares, I998, págs. $87-93$.

TAYlor, P., Freedom of Religion. UN and European Human Rights Law and Practice, Cambridge, Cambridge University Press, 2005.

Zoethout, C. M., «Rethinking Adjudication under the European Convention», en Temperman, J., The Lautsi Papers: Multidisciplinary Reflections on Religious Symbols in the Public School Classroom, cit., págs. 4I3-426. 